\title{
Case Reports: Treatment-Resistant Schizophrenia with Severe Type 2 Diabetes Mellitus Treated with Clozapine
}

\author{
Junji Gon, Shinji Sakamoto, Manabu Takaki* \\ Department of Neuropsychiatry, Okayama University Graduate School of Medicine, Okayama, Japan \\ Email: *manabuta@okayama-u.ac.jp
}

Received 9 October 2015; accepted 8 January 2015; published 11 January 2016

Copyright (C) 2016 by authors and Scientific Research Publishing Inc.

This work is licensed under the Creative Commons Attribution International License (CC BY). http://creativecommons.org/licenses/by/4.0/

C)

\begin{abstract}
Objective: Clozapine is regarded as the most effective drug for treatment of schizophrenia but has complex adverse effects associated with hyperglycemia and diabetes mellitus. Method: We report that clozapine was very effective to treat positive, negative, and cognitive symptoms and well tolerated to a treatment-resistant schizophrenia patient with severe type 2 diabetes mellitus (DM) under cautious blood-sugar monitoring. Results: Clozapine itself and discontinuation of other psychotropic and anticholinergic agents after switching may improve cognitive function and adherence to the treatment regimens for schizophrenia and DM. Conclusion: Clozapine can be administered to treatment-resistant schizophrenia patients even with severe DM with caution.
\end{abstract}

\section{Keywords}

Clozapine, Treatment-Resistant Schizophrenia, Type 2 Diabetes Mellitus, Brief Assessment of Cognition in Schizophrenia Japanese Version

\section{Introduction}

Clozapine (CZP), one of the second-generation antipsychotics, is regarded as the most effective drug for treatment of schizophrenia [1]. In spite of the low risk of extrapyramidal adverse effects, complex adverse effects associated with hyperglycemia and diabetes mellitus (DM) have been reported [2]. Because the use of CZP is limited to severe hyperglycemia and DM, there are few reports of clozapine administration to schizophrenia patients with severe type $2 \mathrm{DM}$. We report that CZP was very effective and well tolerated to a treatment-resistant schizophrenia patient with severe type $2 \mathrm{DM}$.

*Corresponding author.

How to cite this paper: Gon, J., Sakamoto, S. and Takaki, M. (2016) Case Reports: Treatment-Resistant Schizophrenia with Severe Type 2 Diabetes Mellitus Treated with Clozapine. Open Journal of Psychiatry, 6, 61-64.

http://dx.doi.org/10.4236/ojpsych.2016.61006 


\section{Case Presentation}

A 17-year-old man was admitted to a psychiatric practitioner with complaints of persecutory delusion and violence toward his parents from the onset. We diagnosed as schizophrenia according to DSM-IV. Various antipsychotics were administered, but his symptoms did not improve. He was hospitalized many times before he was admitted to our hospital at 29 years old. His antipsychotic history included over $12 \mathrm{mg} /$ day haloperidol for more than five years, $350 \mathrm{mg} /$ day zotepine for more than four years, $20 \mathrm{mg}$ /day olanzapine for a year and a half, $400 \mathrm{mg}$ /day quetiapine for two months, and $8 \mathrm{mg} /$ day risperidone for more than four years. We urged him to take a blood sugar test many times, but he refused out for fear. At 31 years old, he revealed severe uncontrolled type $2 \mathrm{DM}$ (fasting blood sugar: $499 \mathrm{mg} / \mathrm{dl}, \mathrm{Hb}_{\mathrm{Alc}}: 13.1 \%$ ), and hospitalized. Although hyperglycemia improved within a few weeks, it became exacerbated after discharge due to excessive eating.

At 32 years old, he was hospitalized for administration of CZP and treatment of DM. His psychotropic drugs at the time of hospitalization were: $30 \mathrm{mg} /$ day haloperidol, $350 \mathrm{mg} /$ day zotepine, and $10 \mathrm{mg} /$ day risperidone, in addition to $1000 \mathrm{mg}$ /day sodium valproate, $7 \mathrm{mg}$ /day biperiden, $5 \mathrm{mg} /$ day nitrazepam, and $0.25 \mathrm{mg} /$ day brotizolam. He fulfilled the criteria of treatment-resistant schizophrenia [3]. Abnormal values were not detected in blood tests except random blood sugar $(420 \mathrm{mg} / \mathrm{dl})$ and $\mathrm{Hb}_{\mathrm{A1c}}(11.0 \%)$. After repeated persuasion, we started insulin injection (9 units/day rapid-acting and 8 units/day long-acting), and his blood sugar level decreased. On day 9, the blood sugar was stabilized within the normal range and we tried to start CZP. However, he rejected CZP again because of the adverse effects and long hospitalization for treatment. We argued repeatedly that he could not live a normal life and get a job without treatment for DM and psychotics symptoms, and we hoped to overcome his fear of his "terrifying” neighbors. He accepted our arguments on the 21st day after hospitalization, and $12.5 \mathrm{mg} /$ day CZP was added to his regimen. The dosage was gradually increased to $300 \mathrm{mg} /$ day in 6 weeks. At 6 weeks, he complained sedation and nausea, and his liver enzymes were elevated. The dosage was reduced to $275 \mathrm{mg}$ /day CZP as maintenance. Hallucination and delusion improved, and he exhibited no irritability, anger, or violence. The total Positive and Negative Syndrome Scale (PANSS) score decreased by 26\% (from 99 to 73) and the Brief Assessment of Cognition in Schizophrenia Japanese version (BACS-J) z-score increased by 56\% (from -1.93 to -0.80) (see Figure 1). The blood sugar level improved and oral hypoglycemic agents (described
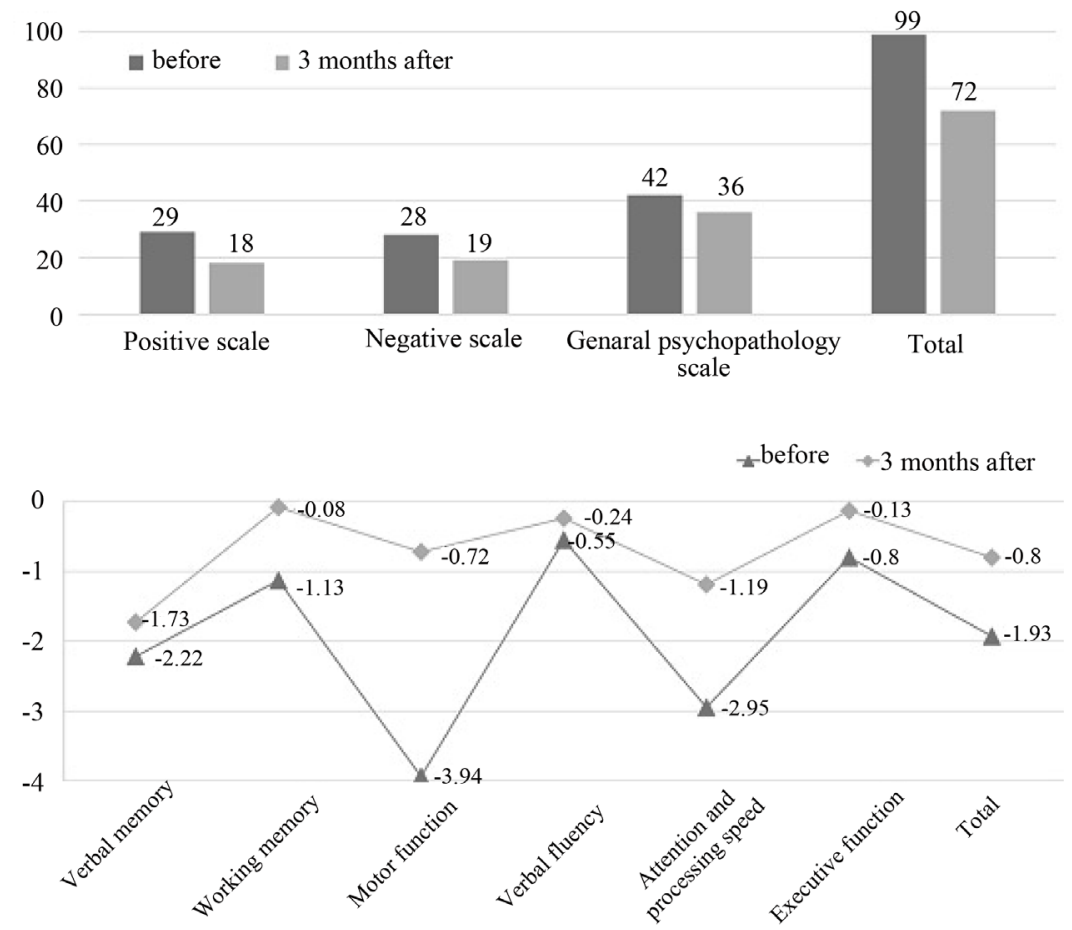

Figure 1. Positive and negative symptom scale (PANSS) (upper) and brief assessment of cognition in schizophrenia (BACS)-J (z-score) (lower) before administration of clozapine and after 3 three months treatment. 
below) were administered while tapering insulin. $\mathrm{His} \mathrm{Hb}_{\mathrm{A1c}}$ decreased to $5.5 \%$ during the 3-month hospitalization and was stable after discharge. The prescriptions on discharge were $275 \mathrm{mg} / \mathrm{day}$ CZP, $5 \mathrm{mg} /$ day nitrazepam, $100 \mathrm{mg}$ /day vildagliptin, and $0.9 \mathrm{mg} /$ day voglibose. More than one year after discharge, his psychiatric symptoms have not recurred. Though he has not worked, he is always in the good mood and sometimes enjoys finance by internet. Because he is able to continue diet and drug therapy for DM, his $\mathrm{HbA1c}$ is within normal range.

\section{Discussion}

CZP is the most effective pharmacologic treatment for positive symptoms of schizophrenia [1] and more beneficial for negative and cognitive symptoms than other antipsychotics [4]. On the other hand, it may alter glucose homeostasis by increasing peripheral insulin resistance and decreasing insulin secretion because of its affinity for muscarinic M3 receptors [5]. Several studies also reported that CZP inhibits glucose transporter expression, which hampers glucose transport through the cell membrane [6] [7]. Based on these mechanisms, the association between diabetic ketoacidosis (DKA) and CZP is strong, and the incidence of DKA with antipsychotics was most frequent in CZP [8]. A grossly elevated HbA1c level is reported in schizophrenia patients with DM presenting with DKA, and these patients are suggested to have undiagnosed DM for at least several weeks before the DKA episode [8]. Although we may discourage the administration of CZP due to the risk of noncompliance, discontinuation of DM treatment or lack of blood sugar monitoring due to severe psychiatric symptoms may subject schizophrenia patients with DM to the risk of life-threatening events such as DKA [8].

When we administrate CZP to schizophrenia patients with severe type 2 DM, two important points are suggested: cautious blood sugar monitoring and improvement of compliance. We checked the blood sugar every two weeks and HbA1c every four weeks following the Clozaril Patient Monitoring Service (CPMS) in Japan. In this case, we monitored glucose almost every day by finger sticks to identify exacerbation of DM as soon as possible. At the point of improvement of compliance, cognitive function may be the most important issue, and CZP is reported to improve cognitive function [4]. Furthermore, discontinuation of other psychotropic and anticholinergic agents improves cognitive function [9] [10]. In our case, after switching to CZP, the chlorpromazine-equivalent dose was reduced from $3030 \mathrm{mg}$ to $550 \mathrm{mg}$, and anticholinergics were stopped. Subsequently, his feeling of illness may have changed to consciousness of the disease and his adherence to the treatment regimens for schizophrenia and DM may be improved.

\section{Conclusion}

We would recommend the administration of CZP to treatment-resistant schizophrenia patients even with severe DM, but with close observation.

\section{Acknowledgements}

This study is partly supported by a grant from Zikei Institute of Psychiatry. We thank Dr. Kaneda for training in BACS-J and Ms. Yabe and Imai for the administration of BACS-J.

\section{References}

[1] Leucht, S., Cipriani, A., Spineli, L., Mavridis, D., Orey, D., Richter, F., Samara, M., Barbui, C., Engel, R.R., Geddes, J.R., Kissling, W., Stapf, M.P., Lässig, B., Salanti, G. and Davis, J.M. (2013) Comparative Efficacy and Tolerability of 15 Antipsychotic Drugs in Schizophrenia: A Multiple-Treatments Meta-Analysis. Lancet, 382, 951-962. http://dx.doi.org/10.1016/S0140-6736(13)60733-3

[2] Haupt, D.W. and Newcomer, J.W. (2001) Hyperglycemia and Antipsychotic Medications. Journal of Clinical Psychiatry, 62, 15-26.

[3] Kane, J.M., Honigfeld, G., Singer, J. and Meltzer, H. (1988) Clozapine in Treatment-Resistant Schizophrenics. Psychopharmacology Bulletin, 24, 62-67. http://dx.doi.org/10.1001/archpsyc.1988.01800330013001

[4] Woodward, N.D., Purdon, S.E., Meltzer, H.Y. and Zald, D.H. (2005) A Meta-Analysis of Neuropsychological Change to Clozapine, Olanzapine, Quetiapine, and Risperidone in Schizophrenia. International Journal of Neuropsychopharmacology, 8, 457-472. http://dx.doi.org/10.1017/S146114570500516X

[5] Chang, S.C. and Lu, M.L. (2012) Metabolic and Cardiovascular Adverse Effects Associated with Treatment with Antipsychotic Drugs. Journal of Experimental \& Clinical Medicine, 4, 103-107. 
http://dx.doi.org/10.1016/j.jecm.2012.01.007

[6] Tovey, E., Rampes, H. and Livingstone, C. (2005) Clozapine-Induced Type-2 Diabetes Mellitus: Possible Mechanisms and Implications for Clinical Practice. Journal of Psychopharmacology, 19, 207-210. http://dx.doi.org/10.1177/0269881105049043

[7] Liu, H., Ji, C., Xiao, W. and Wang, G. (2010) Effects of Clozapine and Its Metabolites on Expression of Glucose Transporter 2 Located in Cell Membrane of Isolated Rat's Islets. European Psychiatry, 25, 800. http://dx.doi.org/10.1016/S0924-9338(10)70791-4

[8] Henderson, D.C., Cagliero, E., Copeland, P.M., Louie, P.M., Borba, C.P., Fan, X., Freudenreich, O. and Goff, D.C. (2007) Elevated Hemoglobin A1c as a Possible Indicator of Diabetes Mellitus and Diabetic Ketoacidosis in Schizophrenia Patients Receiving Atypical Antipsychotics. Journal of Clinical Psychiatry, 68, 533-541. http://dx.doi.org/10.4088/JCP.v68n0407

[9] Kitajima, R., Miyamoto, S., Tenjin, T., Ojima, K., Ogino, S., Miyake, N., Fujiwara, K., Funamoto, Y., Arai, J., Tsukahara, S,, Ito, Y., Tadokoro, M., Anai, K., Kaneda, Y. and Yamaguchi, N. (2012) Effects of Tapering of Long-Term Benzodiazepines on Cognitive Function in Patients with Schizophrenia Receiving a Second-Generation Antipsychotic. Progress in Neuro-Psychopharmacology \& Biological Psychiatry, 36, 300-306. http://dx.doi.org/10.1016/j.pnpbp.2011.11.008

[10] Ogino, S., Miyamoto, S., Tenjin, T., Kitajima, R., Ojima, K., Miyake, N., Funamoto, Y., Arai, J., Tsukahara, S., Ito, Y., Tadokoro, M., Anai, K., Tatsunami, S., Kubota, H., Kaneda, Y. and Yamaguchi, N. (2011) Effects of Discontinuation of Long-Term Biperiden Use on Cognitive Function and Quality of Life in Schizophrenia. Progress in Neuro-Psychopharmacology \& Biological Psychiatry, 35, 78-83. http://dx.doi.org/10.1016/j.pnpbp.2010.08.030 